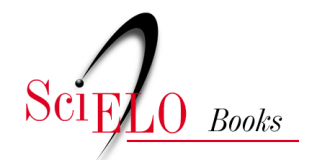

\title{
Entre el 'último hablante' y el Estado: el caso de la lengua amazónica taushiro (Perú)
}

\author{
Agustín Panizo \\ Gerardo García \\ Rosaleen Howard
}

\section{SciELO Books / SciELO Livros / SciELO Libros}

PANIZO, A., GARCÍA, G, and HOWARD R. Entre el 'último hablante' y el Estado: el caso de la lengua amazónica taushiro (Perú). In: HABOUD BUMACHAR, M., SÁNCHEZ AVENDAÑO, C., and GARCÉS VELÁSQUEZ, F., eds. Desplazamiento lingüístico y revitalización: reflexiones y metodologías emergentes [online]. Quito: Editorial AbyaYala, 2020, pp. 249-271. Desafíos en la Diversidad collection, n. 2. ISBN: 978-9978-10541-2. http://doi.org/10.7476/9789978105726.0011.

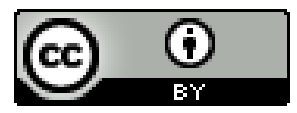

All the contents of this work, except where otherwise noted, is licensed under a Creative Commons Attribution 4.0 International license.

Todo o conteúdo deste trabalho, exceto quando houver ressalva, é publicado sob a licença Creative Commons Atribição 4.0.

Todo el contenido de esta obra, excepto donde se indique lo contrario, está bajo licencia de la licencia Creative Commons Reconocimento 4.0. 


\title{
Entre el 'último hablante' y el Estado: el caso de la lengua amazónica taushiro (Perú) $)^{1}$
}

\author{
Agustín Panizo² \\ Gerardo García ${ }^{3}$ \\ Rosaleen Howard ${ }^{4}$
}

\section{Resumen}

El presente artículo reflexiona sobre el papel del Estado en los procesos de revitalización lingüística a partir de la experiencia peruana de documentación de la lengua taushiro. Sobre esto, Evans (2010) resalta la importancia de la existencia de "abogados" externos a una comunidad de hablantes de una lengua amenazada que puedan ayudar a la comunidad en el proceso de revitalización de su lengua. Este artículo tiene como principales objetivos, por un lado, presentar la metodología de los proyectos de documentación lingüística del Ministerio de Cultura del Perú y, por otro lado, identificar los beneficios que puede representar para los hablantes la intervención gubernamental en los procesos de revitalización lingüística en contraste con proyectos emprendidos por otro tipo de actores. El estudio es de naturaleza descriptiva, basada en los datos recopilados mediante el trabajo de campo lingüístico y sociocultural llevado a cabo por lingüistas-funcionarios del Ministerio de Cultura. Asimismo, contextualiza el caso de la lengua taushiro con referencia a la literatura secundaria pertinente. Una de las conclusiones más relevantes del estudio es que una intervención gubernamental en los procesos de revitalización lingüística puede, como sucedió en el caso descrito, garantizar beneficios materiales para la comunidad de hablantes de la lengua en peligro, así como ampliar el abordaje del trabajo de documentación tantas veces restringido al lingüístico a un acercamiento además social y cultural.

En este documento ofrecemos una reflexión sobre el rol que puede jugar el Estado, dadas las condiciones institucionales que se prestan a ello, en los procesos de revitalización lingüística de las lenguas indí-

1 Un agradecimiento a Mercedes Mere Chávez (Universidad Nacional Federico Villarreal) por la revisión del manuscrito para la mejora en la presentación de los cuadros y gráficos.

2 Pontificia Universidad Católica del Perú y Wikitongues.

3 Ministerio de Cultura del Perú y Universidad Nacional Federico Villarreal.

4 Newcastle University, Reino Unido. 
genas amenazadas de América Latina a partir de la experiencia con la lengua indígena taushiro de la Amazonía peruana (de familia aislada) ${ }^{5}$.

Como bien señala Hinton (2011), el término "revitalización" se aplica de manera muy generalizada para designar escenarios que habría que distinguir, como el "reclamo" y el "resurgimiento" de una lengua, en los casos en los que quedan pocos o ningún hablante activo. Asimismo, con respecto a la terminología que se maneja actualmente, en lugar de lenguas "muertas" o "desaparecidas" convendría hablar de lenguas "dormidas" o "recordadas" cuando la lengua ya no tiene comunidad de hablantes. De este modo, dadas las condiciones apropiadas, el "despertar" de la lengua quedaría como una posibilidad.

Para que este despertar ocurra, como ha sido el caso de la lengua celta cornish (o córnico) en el Reino Unido (Grenoble \& Whaley, 2006, pp. 45-48) y el muy conocido caso del hebreo en Israel, entre otros, por un lado, se necesita una profunda motivación social, cultural o política que viene de parte de un grupo de hablantes, o de hablantes potenciales, que se encarguen de hacer vivir la lengua, aunque sea para ciertas funciones limitadas. Se requiere de una agencia 'egocéntrica' por así decirlo, una voluntad propia de parte del hablante, para que la lengua se despierte.

En el caso de las lenguas amerindias, su pérdida a través de los siglos se debe a una historia de colonización violenta, de violencia simbólica, y de "muerte silenciosa" en las palabras de Adelaar (1999). Estas circunstancias explican por qué, en el presente, la sola

5 El Perú es el tercer país con mayor cantidad de lenguas indígenas de Suramérica (después de Brasil y Colombia) ya que cuenta con 48 lenguas indígenas actualmente identificadas oficialmente. Para más detalle se puede ver Mapa Etnolingüístico del Perú (Decreto Supremo No 011-2018-MINEDU) y, en amplitud, los anexos del trabajo de Luna y Sánchez (2019). 
voluntad de un hablante de hablar su lengua rara vez será suficiente para sobreponerse al peso de la historia, para "darle paso atrás al desplazamiento lingüístico” en la formulación de Fishman (1991, 2000). Estamos viendo hoy en día cómo el revivir de las lenguas minorizadas muchas veces es producto, por lo menos en sus etapas iniciales, de una interacción y una colaboración entre algún aliado exterior a la comunidad de hablantes, y los hablantes mismos. Tal aliado puede ser un misionero, académico, miembro de una ONG, agente del Estado, o algún individuo cuya identidad combina más de uno de estos papeles. La importancia de estos "abogados" por la documentación lingüística, y revitalización en los casos factibles, es un tema tocado por Evans (2010, pp. 206-210), por ejemplo.

En la propuesta para esta presentación, los convocantes nos propusieron el reto de buscar la forma idónea de ejercer una documentación activa o participativa ${ }^{6}$, en toda la amplitud de este concepto, a favor de las lenguas en peligro de desaparición en América Latina. Entre las preguntas que nos hicieron figuraban: (i) ¿Cómo evitar las infranqueables brechas que se dan entre los niveles macro y micro? y (ii) ¿Cómo pasar exitosamente de las políticas a la implementación?

Como para confirmar las dificultades que subyacen a estas preguntas, en el libro Indigenous Language Revitalization in the Americas (Coronel-Molina \& McCarty, 2016), Gustafson et al. observan que, en términos generales, y a pesar de los cambios en la política oficial de reconocimiento de la diversidad cultural y lingüística que ha habido en la región latinoamericana en las últimas décadas, 'el Estado

6 Se conoce como documentación participativa aquella en la que el propio pueblo indígena participa de manera activa en el proceso de documentación de su lengua. Un gran difusor de esta corriente es el lingüista mexicano José Flores Farfán, quien coordinó la traducción al castellano del libro Bases de la documentación lingüistica (Haviland \& Flores, 2011). 


\section{2}

sigue socavando las condiciones materiales para que haya autodeterminación lingüística y social entre el sector indígena' (Gustafson et al., 2016, p. 35, traducción nuestra) y que, dada esta situación, 'los esfuerzos más prometedores para una política de revitalización surgen de los movimientos de base y de las redes translocales' (Gustafson et al., 2016, p. 35, traducción nuestra).

A continuación, presentamos nuestro estudio de caso que enfoca el papel del Estado en un país multilingüe como es el Perú en los esfuerzos por documentar y apoyar la reclamación de una lengua indígena en situación crítica a partir de un marco normativo presente (la Ley n. ${ }^{\circ}$ 29735, Ley de lenguas indígenas u originarias ${ }^{7}$, el reglamento de la Ley n. 29735 y la Política Nacional de Lenguas Originarias, Tradición Oral e Interculturalidad). El Ministerio de Cultura del Perú emprendió, por primera vez en el año 2017, un trabajo de documentación lingüística de dos lenguas en situación crítica: la lengua taushiro, que como ya se ha indicado es de familia aislada, y la lengua resígaro, de la familia lingüística Arawak. El trabajo fue sistematizado y presentado a inicios de 2018. Para los fines de este estudio, por estar la sistematización de los datos sobre resígaro todavía en progreso, daremos algunos detalles del caso de esta lengua y examinaremos el caso de taushiro de manera más profundizada.

La categoría de "situación crítica" corresponde al extremo negativo de la escala de vitalidad de las lenguas, tal como se puede apreciar en el siguiente cuadro elaborado en base al Reglamento de

7 La Ley n. 29735 fue aprobada el 2011 y tiene por objeto "precisar el alcance de los derechos y garantías individuales y colectivas que, en materia lingüística, se establecen en el artículo 48 de la Constitución Política del Perú" (artículo 1, numeral 1.1. de la Ley n. $\left.{ }^{\circ} 29735\right)$. 
la Ley n. $^{\circ} 29735^{8}$ y al documento de la UNESCO (2003) sobre vitalidad lingüística:

\section{Cuadro 1 \\ Escala de vitalidad de las lenguas indígenas u originarias en el Perú}

\begin{tabular}{|c|l|l|}
\hline n. $^{\circ}$ & Categoría & \multicolumn{1}{c|}{ Descripción } \\
\hline 1 & $\begin{array}{l}\text { Lengua a } \\
\text { salvo o vital } \\
2\end{array}$ & $\begin{array}{l}\text { Lengua } \\
\text { vulnerable } \\
\text { todongua es hablada por todas las generaciones en } \\
\text { neración a otra es continua. }\end{array}$ \\
\hline 3 & $\begin{array}{l}\text { Lengua } \\
\text { en peligro } \\
\text { La mayoría de niños y niñas habla la lengua, pero su } \\
\text { (por ejemplo, al hogar familiar). }\end{array}$ \\
\hline 4 & $\begin{array}{l}\text { La lengua es hablada por la generación de los padres, } \\
\text { madres, abuelas o abuelos, pero en ámbitos restringi- } \\
\text { dos. Los niños y niñas no adquieren la lengua en sus } \\
\text { familias como lengua materna. }\end{array}$ \\
\hline 5 & $\begin{array}{l}\text { seriamente } \\
\text { en peligro }\end{array}$ & $\begin{array}{l}\text { Solamente los abuelos, abuelas y las personas de las } \\
\text { generaciones mayores hablan la lengua, en ámbitos } \\
\text { restringidos. Los padres y madres, si bien pueden } \\
\text { comprenderla, no la hablan entre sí, ni tampoco con } \\
\text { sus hijos. }\end{array}$ \\
\hline 6 & $\begin{array}{l}\text { Lengua } \\
\text { extinta }\end{array}$ & $\begin{array}{l}\text { Muy pocos hablantes se comunican en esta lengua. } \\
\text { Generalmente, la generación de los bisabuelos. }\end{array}$ \\
\hline
\end{tabular}

Fuente: UNESCO (2003, pp. 6-8).

8 Esta clasificación es oficial en el Perú tras su inclusión en el Decreto Supremo n. ${ }^{\circ}$ 004-2016-MC que aprueba el Reglamento de la Ley n. ${ }^{\circ} 29735$. Para su elaboración, se trabajó sobre la base de la clasificación presentada en UNESCO (2003). 


\section{4}

Actualmente, el Perú cuenta con un grupo de lenguas indígenas en situación crítica, mayoritariamente lenguas amazónicas:

\section{Cuadro 2}

\section{Lenguas originarias peruanas en situación crítica}

\begin{tabular}{|l|l|l|l|}
\hline \multicolumn{1}{|c|}{$\begin{array}{c}\text { Familia } \\
\text { lingüística }\end{array}$} & \multicolumn{1}{|c|}{ Lengua } & \multicolumn{1}{c|}{ Ubicación } & \multicolumn{1}{c|}{ Hablantes } \\
\hline tupí-guaraní & omagua & Loreto & 2 \\
\hline \multirow{2}{*}{ arawak } & chamicuro & Loreto & 9 (1 hablante fluido $)$ \\
\cline { 2 - 4 } & resígaro & Loreto & 3 (1 hablante fluido $)$ \\
\cline { 2 - 4 } & Iñapari & Madre de Dios & $\begin{array}{l}5(4 \text { hablantes } \\
\text { fluidos })\end{array}$ \\
\hline \multirow{2}{*}{ muniche } & munichi & $\begin{array}{l}\text { San Martín } \\
\text { (Yurimaguas })\end{array}$ & 1 \\
\hline aislada & taushiro & Loreto & $5(1$ hablante fluido $)$ \\
\hline pano & iskonawa & Ucayali & 4 \\
\hline
\end{tabular}

Fuente: Adaptación de los autores a partir del Documento Nacional de Lenguas Originarias (MINEDU, 2013).

La lengua taushiro cuenta con un único hablante fluido identificado, el señor Amadeo García García, que en su lengua fue llamado por sus semejantes como O'kwanuka ('hermano menor'). El señor García tiene 69 años, nació el 30 de octubre de 1950 y reside actualmente en el Centro Poblado de Intuto, la capital del distrito de El Tigre en la provincia de Loreto y departamento del mismo nombre, en la selva nororiental del Perú. En el caso de la lengua resígaro, aunque se pensaba que quedaba un único hablante, el señor Pablo Andrade Ocagane, durante el trabajo de documentación realizado con él, nos informó de otros dos hablantes de la lengua, con los cuales, sin embargo, no se mantiene contacto continuo. Se trata de dos 
familiares de Pablo Andrade, una señora y su hijo, hoy residentes en Bogotá y en Pucallpa, respectivamente?

El trabajo con las lenguas taushiro y resígaro fue emprendido en un contexto de emergencia debido al avanzado proceso de desaparición de estas lenguas. En efecto, desde hace algún tiempo, distintos reportajes periodísticos habían dado cuenta de que la lengua taushiro solo era hablada por Amadeo García, a quien, de forma un tanto sensacionalista, se había llamado el "último taushiro". Un artículo del diario New York Times recoge mucha información sobre Amadeo García (Casey, 2017), con un sesgo periodístico reflejado en el uso de esta denominación. Desde el Ministerio de Cultura no se comparte esta calificación, como queda claro en esta observación:

Tras esta intervención [de documentación lingüística] se han podido romper mitos como el decir que Amadeo García es 'el último Taushiro'. Por el contrario, se ha podido identificar a un grupo de personas que se consideran pertenecientes al pueblo Taushiro [...] (Ministerio de Cultura, 2018, p. 15).

La cierta notoriedad de Amadeo García que fomentaban los reportajes periodísticos lo había puesto en una situación de vulnerabilidad que le trajo no pocos problemas, tras los cuales su historia cayó un tanto en el olvido y la desatención. Sin embargo, a fines del 2016, el Ministerio recibió en Lima la visita de dos personas que conocían a don Amadeo García y que manifestaron su preocupación por su situación, a la vez que instaron al Ministerio a emprender un trabajo de recuperación de la lengua con Amadeo $^{10}$. Ambos ayuda-

9 Posteriormente, en una visita de 2019, el señor Pablo Andrade nos presentó a cuatro personas consideradas hablantes de resígaro, con lo que se alcanza el número de cinco hablantes, incluido él, en distinto grado de fluidez.

10 Una de estas personas fue el docente retirado Fidel Aquituari, una persona cercana a don Amadeo y residente de Intuto, quien ha sido un importante apoyo 


\section{6}

ron a establecer el contacto con él y a programar el trabajo de atención a él y a su lengua.

En el caso de la lengua resígaro, en diciembre de 2016, se supo a través de reportes venidos de la comunidad de Nueva Esperanza, en la zona de Pebas, en la cuenca del río Amazonas, del cruento asesinato de una mujer, Rosa Andrade Ocagane, de quien se afirmaba que era la última hablante de la lengua resígaro (Rivadeneyra, 2016). Esto encendió las alertas y la noticia incluso trascendió las fronteras del país. En una de las notas periodísticas aparecidas en el diario El País de España tras la muerte de Rosa Andrade, el Ministerio de Cultura informó que justamente había establecido poco antes contacto con Rosa y con su hermano Pablo Andrade Ocagane para trabajar en la documentación de su lengua, y manifestó su compromiso de continuar con su propósito y llevar a cabo el proyecto de la mano del señor Pablo (Fowks, 2016).

\section{Figura 1 \\ Amadeo García, hablante de la lengua taushiro}

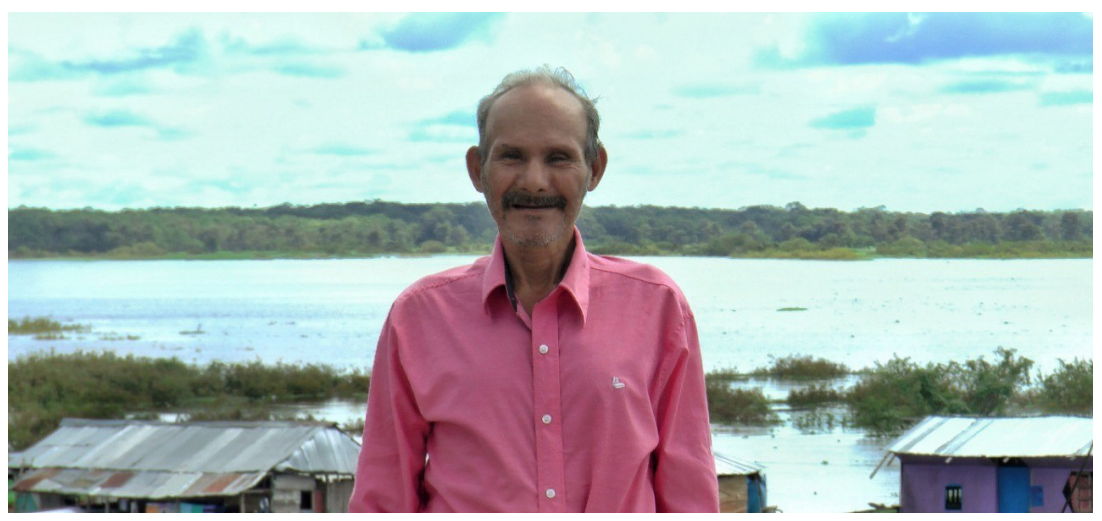

Fotografía: Lee Bendezú (Ministerio de Cultura del Perú).

en el trabajo posterior. 


\section{Figura 2}

Pablo Andrade, hablante de la lengua resígaro

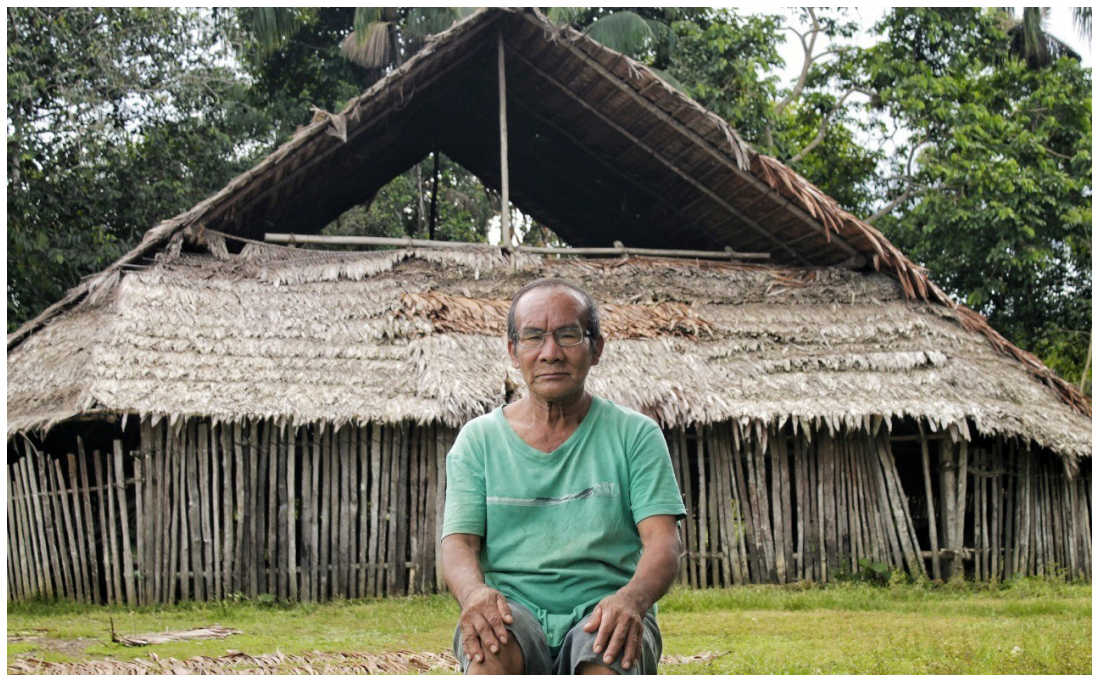

Fotografía: Lee Bendezú (Ministerio de Cultura del Perú).

Ambos proyectos de documentación se realizaron el $2017^{11}$. En el documento de sistematización de este trabajo, el Ministerio de Cultura del Perú propone su metodología basada en cuatro fases: (1) diagnóstico, (2) documentación de la lengua y la cultura, (3) acopio y procesamiento de la información y (4) devolución al pueblo indígena y difusión. El propósito de la institución es aplicar la metodología en la atención a otras cinco lenguas que entran en la categoría de situación crítica: omagua, chamicuro, iñapari, munichi e iskonawa (Ministerio de Cultura, 2018).

11 Ambos procesos de documentación fueron coordinados por el lingüista Gerardo García Chinchay, especialista de la Dirección de Lenguas Indígenas y co-autor del presente estudio. Los lingüistas encargados de las tareas de campo, procesamiento y análisis de los datos fueron Solaens Vilela, para el taushiro, y Lee Bendezú, para el resígaro. 


\section{8}

De acuerdo con las pautas establecidas por el Ministerio, en la etapa de diagnóstico, 'se hace una revisión bibliográfica que concluye en un estado de la cuestión de la lengua en situación crítica', luego de lo cual 'se identifica al hablante o hablantes fluidos de la lengua', tras una evaluación que considera tanto competencia lingüística como 'las condiciones de vida en las que se encuentra el hablante'. Aquí se encuentra una primera característica distintiva del quehacer de esta entidad estatal, que busca primero garantizar las 'condiciones de vida y salud' del colaborador y 'crear una red de aliados para el trabajo con el pueblo indígena'. El trabajo con el hablante exige un acuerdo en el que 'se establecen las condiciones de la colaboración y se garantiza su participación a través del desarrollo de todo el proyecto' (Ministerio de Cultura, 2018, p. 6).

Figura 3

Sesión de documentación con Amadeo García en Iquitos, 2017

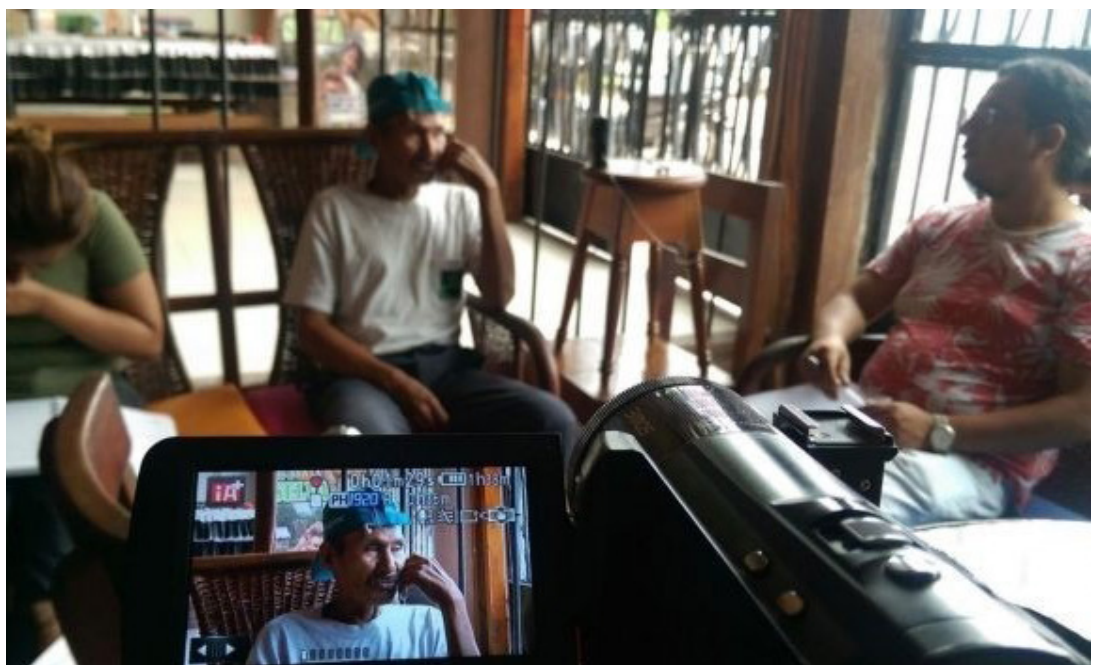

Fotografía: Lee Bendezú (Ministerio de Cultura del Perú). 
La segunda etapa, consistente en la documentación cultural y lingüística, es emprendida por un equipo técnico compuesto al menos de un lingüista, un antropólogo y un comunicador audiovisual. Este equipo profundiza en la revisión bibliográfica sobre la lengua y la cultura, para luego entrar a la labor de campo propiamente dicha, en la que se trabaja con el hablante y otros miembros de su pueblo, registrando información para la construcción de una base de datos tanto fonético-lexicales como discursivos: relatos sobre la vida cotidiana del hablante, sus prácticas culturales y actividades productivas, historia de vida, así como la tradición oral de su pueblo, que incluye narraciones y descripciones sobre su visión del mundo, su arte tradicional, sus prácticas alimentarias, y otro tipo de información (Ministerio de Cultura, 2018, pp. 6-7).

En este proceso, se siguen los protocolos del Ministerio de Cultura para el relacionamiento con pueblos indígenas que 'garanticen el respeto a sus conocimientos tradicionales y a sus prácticas culturales', un elemento que es enfatizado por los funcionarios ${ }^{12}$.

La tercera etapa es el acopio y el procesamiento de la información, que incluye un trabajo de campo y de gabinete. El resultado es una cantidad creciente de archivos procesados que son almacenados física y digitalmente en el Ministerio de Cultura, y que luego pasarán a formar parte del Archivo Nacional de Lenguas Indígenas del Perú, repositorio previsto en la normativa nacional que incluirá, entre otras, la siguiente información:

12 Estos protocolos hacen referencia a ciertas pautas que deben seguirse al momento de ingresar a trabajar en una comunidad o pueblo indígena, como la necesidad de entrar con alguna autorización oficial, de solicitar permiso expreso de la autoridad indígena local, de informar adecuadamente sobre las actividades a realizar, entre otras pautas que deben seguirse obligatoriamente, tratándose de acciones en representación del Estado. 


\section{0}

- Bibliografía recopilada

- Lista de Swadesh

- Grabaciones en audio y video del hablante y su entorno

- Transcripciones de los archivos de audio y video en lengua indígena

- Traducciones de los archivos al castellano

- Registro fotográfico

- Datos de contacto de investigadores

- Memoria documentada del proceso (Ministerio de Cultura, 2018, p. 7).

\section{Figura 4}

\section{Pablo Andrade (hablante de resígaro)} entrevistando a César Capino en Pebas, Loreto

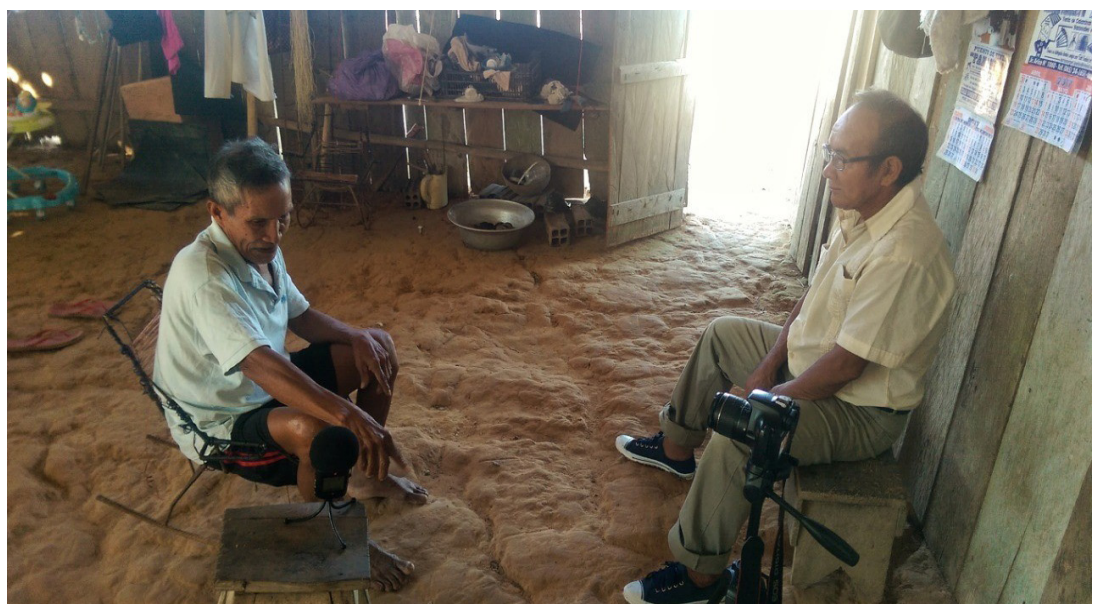

Fotografía: Lee Bendezú (Ministerio de Cultura del Perú).

La cuarta etapa consiste en la devolución al pueblo indígena y difusión. El primer elemento 'busca el retorno de la información sobre la lengua, así como la experiencia de documentación a fin de que los integrantes del pueblo indígena tomen conciencia sobre el estado de 
su lengua, se apropien del proceso y sus resultados y se involucren en iniciativas de para su recuperación o difusión'. Por su parte, el segundo se propone 'informar a la sociedad en su conjunto sobre la existencia de la lengua, el pueblo indígena poseedor de ella, su historia, las razones que la han puesto en riesgo, así como informar sobre los derechos lingüísticos y promover su valoración' (Ministerio de Cultura, 2018, p. 8).

Como acciones de difusión, el Ministerio menciona las siguientes:

- El desarrollo de una Plataforma web que reúne los resultados públicos y materiales audiovisuales de los procesos desarrollados.

- El diseño e implementación de aplicaciones móviles para el conocimiento de las lenguas indígenas que contienen frases y palabras de la lengua tanto escritas como en audio, en un menú sencillo que permita a niños y jóvenes un primer acercamiento a la lengua y la cultura de muchos pueblos indígenas peruanos.

- La producción de documentales en los que se da voz a los hablantes de las lenguas indígenas a fin de mostrar la lengua en riesgo, así como la cultura del pueblo indígena poseedor de la lengua.

- El desarrollo de publicaciones, folletos, material de divulgación (Ministerio de Cultura, 2018, p. 8).

Ahora bien, el Ministerio de Cultura peruano ha desarrollado esta metodología, como dijimos, a partir de un trabajo piloto con dos primeras lenguas en situación crítica: taushiro y resígaro. Sin embargo, el documento publicado con la sistematización ofrece únicamente como ejemplo el trabajo con la lengua taushiro.

El trabajo de revisión bibliográfica se compone en gran parte de los materiales reunidos y elaborados por la lingüista Neftalí Ali- 
cea Ortiz en los años 70 del siglo XX (Ministerio de Cultura, 2018, p. 9). De hecho, la relación histórica de los hablantes de la lengua taushiro con Alicea tuvo repercusiones críticas para su supervivencia como lengua viva. Alicea, natural de Puerto Rico, llegó al Perú a realizar investigaciones sobre el pueblo Taushiro y su lengua a inicios de los años 70. Fue enviada por el Instituto Lingüístico de Verano, entidad norteamericana que tiene el propósito de estudiar las lenguas originarias, muchas veces antes desconocidas por la comunidad científica, con el fin de evangelizar en su propia lengua a los pueblos indígenas de distintas partes del mundo. Esta institución ha sido criticada (Stoll, 1984) por los distintos efectos que su presencia ha tenido entre los pueblos indígenas. De hecho, el caso de Alicea va más allá de un simple contacto evangelizador y de investigación lingüística, pues en determinado momento ella decide tomar en adopción a los hijos de Amadeo García, el hablante taushiro con el que trabajaba, y llevarlos a vivir con ella a Puerto Rico (Casey, 2017). Si bien Amadeo sigue en contacto con sus hijos, ellos, ahora de adultos y lejos del medio ambiente de su uso, no hablan taushiro.

Una característica distintiva del trabajo lingüístico comandado por el Ministerio se presenta en este propósito de la fase diagnóstico: el trabajo de mejoramiento de las condiciones de vida del hablante de taushiro antes de iniciar el trabajo con él:

[...] se consideró que Amadeo García requería alcanzar condiciones básicas antes de emprender el proyecto. Debido a esto, desde el Ministerio de Cultura se realizaron las coordinaciones para inscribirlo en el Seguro Integral de Salud (SIS), un organismo estatal que brinda aseguramiento público en salud, principalmente a poblaciones vulnerables y en el Programa Pensión 65, que entrega una subvención económica a adultos mayores que superan los 65 años de edad y que viven en extrema pobreza. Además, se hicieron mejoras a su vivienda y se la dotó de energía eléctrica en coordinación con el gobierno local (Ministerio de Cultura, 2018, p. 9). 
En la fase de documentación de la lengua y la cultura, se trabajó con el hablante y con la comunidad y se diseñaron e implementaron los instrumentos de recojo de información, así como los protocolos de relacionamiento con la comunidad. Uno de los productos interesantes de esta etapa es el árbol genealógico que se logró elaborar, reconstruyendo las relaciones de parentesco de Amadeo García con los únicos dos clanes taushiro que se mantienen hoy: Atontuitua y Einontuitua. En dicho árbol se categoriza a cada miembro según su competencia en la lengua: si la hablaba o no, a partir de la información dada por el propio Amadeo o reportada por investigadores que se ocuparon antes del tema.

\section{Figura 5}

\section{Árbol genealógico parcial de Amadeo García García, hablante fluido de la lengua taushiro}

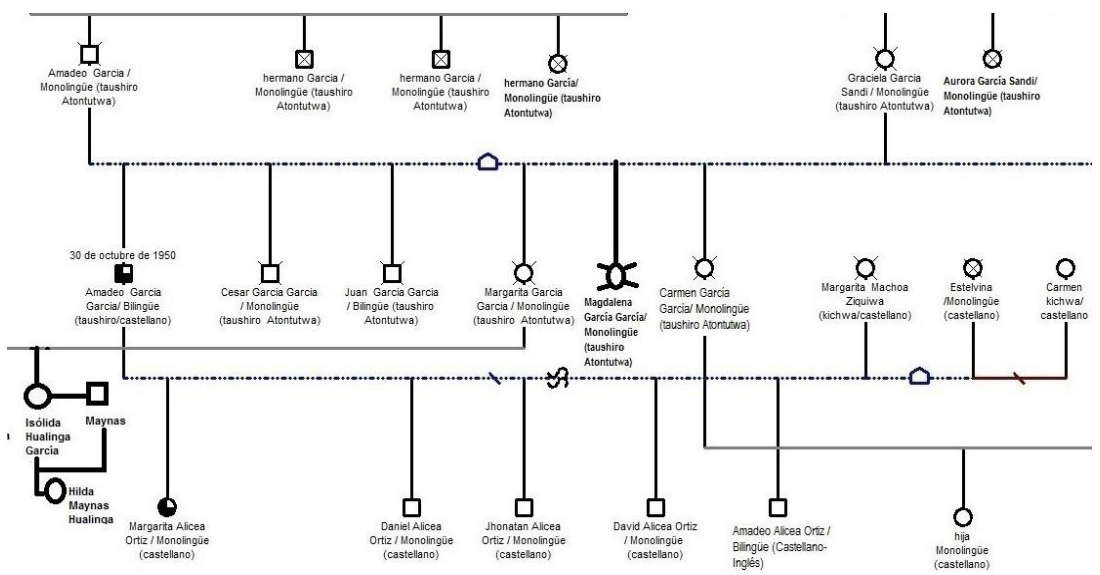

Fuente: elaboración del equipo de documentación de la lengua taushiro del Ministerio de Cultura del Perú.

El árbol genealógico permite ubicar a Amadeo en relación con sus parientes de ambos clanes Atontu'tua y Einontutua que conformaban en un pasado el pueblo Taushiro. Amadeo aparece como único hablante fluido de la lengua, mientras que los otros cuatro "ha- 
blantes" poseen una competencia limitada de la lengua, entienden poco, y hablan poquísimas palabras con las que no logran sostener ni un breve-diálogo con él.

En la etapa posterior, acopio y procesamiento de la información, se procesó y organizó la información recogida. En el siguiente cuadro se reúne los resultados del proceso de documentación de la lengua taushiro tras el trabajo con Amadeo García.

\section{Cuadro 3}

\section{Resultados del trabajo de documentación de la lengua taushiro}

\begin{tabular}{|l|l|l|}
\hline \multicolumn{1}{|c|}{ Producto } & \multicolumn{1}{|c|}{ Conteo } & \multicolumn{1}{c|}{ Observación } \\
\hline $\begin{array}{l}\text { Banco } \\
\text { fonético-léxico }\end{array}$ & 1520 palabras & $\begin{array}{l}\text { Se clasificó los audios por campos se- } \\
\text { mánticos con sus respectivas categorías, } \\
\text { están cortados y transcritos. }\end{array}$ \\
\hline $\begin{array}{l}\text { Elaboración } \\
\text { de App } \\
\text { resígaro }\end{array}$ & 246 palabras & $\begin{array}{l}\text { Excel de palabras usadas para la elabora- } \\
\text { ción del app. } \\
\text { Audios cortados de palabra por palabra } \\
\text { para el app. }\end{array}$ \\
\hline Canciones & 4 & $\begin{array}{l}\text { Están en audio y algunas en video. } \\
\text { Transcritas y traducidas. }\end{array}$ \\
\hline $\begin{array}{l}\text { Cuentos } \\
\text { y narraciones }\end{array}$ & 45 & $\begin{array}{l}\text { Están en audio y/o en video } \\
\text { Están transcritos, no poseen traducción de } \\
\text { palabra por palabra sino más bien de las fra- } \\
\text { ses y la versión en español de los cuentos. }\end{array}$ \\
\hline $\begin{array}{l}\text { Historia } \\
\text { de vida }\end{array}$ & $\begin{array}{l}\text { 1 árbol entrevistas en audio (si están } \\
\text { genealógico } \\
\text { taushiro }\end{array}$ & $\begin{array}{l}\text { transcrito) } \\
14 \text { entrevistas en videos que son parte } \\
\text { de la ideología taushiro } \\
\text { La historia ha sido repartida en base a los } \\
\text { recuerdos del hablante fluido y las entre- } \\
\text { vistas a sus familiares así como amistades. }\end{array}$ \\
\hline
\end{tabular}




\begin{tabular}{|l|l|l|}
\hline $\begin{array}{l}\text { Videos de } \\
\text { Ideología } \\
\text { Taushiro }\end{array}$ & 28 & $\begin{array}{l}\text { Estos son videos de ideología en donde } \\
\text { también hay datos que se han utilizado } \\
\text { para armar la historia }\end{array}$ \\
\hline Fotos & 355 & $\begin{array}{l}\text { Las fotos que se repiten se han elimina- } \\
\text { do en la clasificación de fotos por lugar } \\
\text { y se encontrarán todas (incluyendo las } \\
\text { de baja resolución). }\end{array}$ \\
\hline $\begin{array}{l}\text { Videos de } \\
\text { narraciones } \\
\text { taushiro }\end{array}$ & 69 & $\begin{array}{l}\text { Los videos están clasificados en ideolo- } \\
\text { gía, en cuentos, narraciones y otros. }\end{array}$ \\
\hline
\end{tabular}

Fuente: Ministerio de Cultura (2018, p. 13)

Dada la naturaleza pública de este trabajo, es importante destacar que el Ministerio señala que 'toda la información recogida en la etapa de documentación es almacenada en soportes físicos en los archivos del Ministerio de Cultura, así como en un repositorio digital. Los archivos digitales de la lengua taushiro pasarán a formar parte del Archivo Nacional de Lenguas Indígenas en Situación Crítica' (Ministerio de Cultura, 2018, p. 13).

Finalmente, en la fase de Devolución y difusión 'se informa al pueblo indígena poseedor de la lengua del proceso desarrollado, así como de los avances realizados en su documentación' (Ministerio de Cultura, 2018, p. 14). Para esto, el equipo del Ministerio realizó actividades de devolución en las que participaron el propio Amadeo, su familia, los otros taushiro y miembros de la comunidad, así como autoridades de Intuto. En la actividad central, incluso, se logró una conexión por internet para la conversación de Amadeo con algunos de sus hijos residentes en Puerto Rico. Además, el Ministerio desarrolló dos productos interesantes: una aplicación móvil ${ }^{13}$ llama-

13 Esta aplicación móvil fue elaborada por el Ministerio de Cultura en cooperación técnica con el Instituto de Investigaciones de la Amazonía Peruana (IIAP), en el 
da 'Ivá', que contiene alrededor de dos centenares de palabras o expresiones en taushiro que uno puede oír en la voz de Amadeo, para difundir el conocimiento de la lengua entre niños y jóvenes, principalmente, y un video documental de once minutos titulado 'Ucuañuca. La voz de los Taushiro' ${ }^{14}$.

\section{Figura 6}

\section{Ivá: Aplicativo para teléfonos móviles ${ }^{15}$}
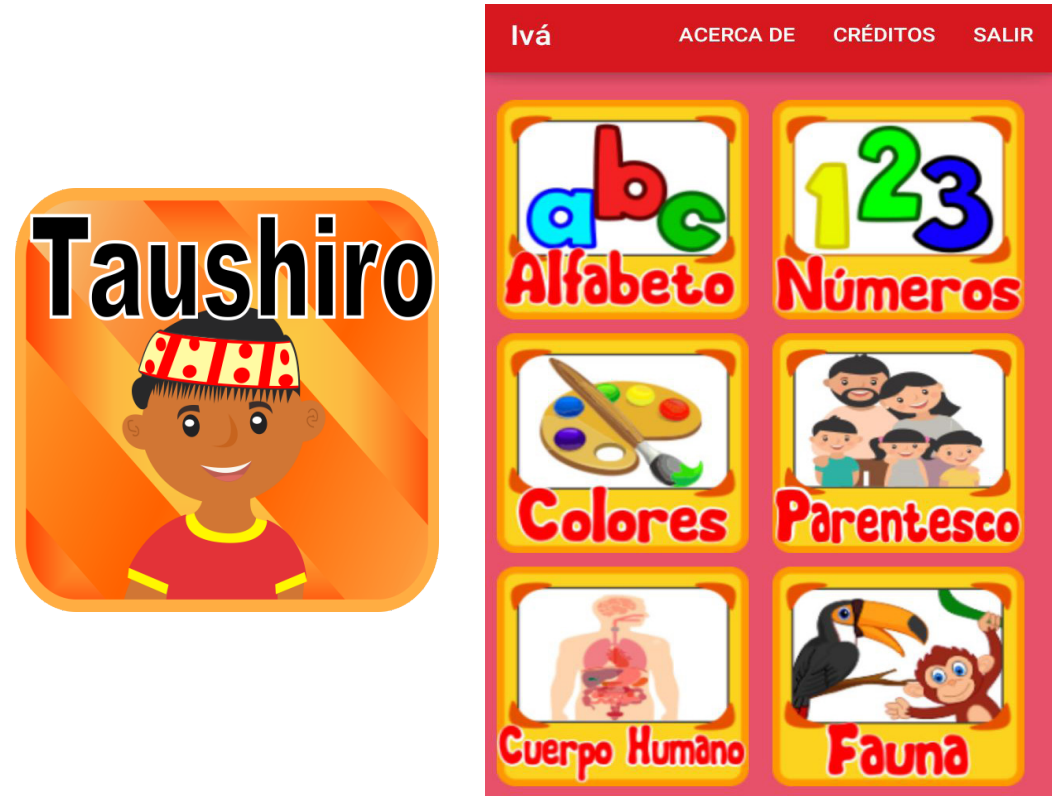

marco de su proyecto Adaptación e Investigación en Sistemas de Información sobre Biodiversidad, Ambiente, Biocomercio y Biotecnología. La aplicación fue coordinada y asesorada técnicamente por el ingeniero Franz Chuje.

14 Este documental fue presentado en Lima en febrero de 2018 y en Iquitos, esta vez con la presencia de Amadeo, tres meses después. Se puede ver en línea en el siguiente enlace: http://minkaprod.com/ucuanuca-la-voz-de-los-taushiro/.

15 Enlaces: https://play.google.com/store/apps/details?id=pe.org.iiap.taushiro\&hl=es_PE 
Este estudio de caso sirve para sacar a luz algunos puntos importantes en cuanto a los procesos de revitalización en general, y en cuanto al papel que puede jugar el Estado en esos procesos, en particular. Como primer punto, y como ya comentamos, en muchos de los casos documentados en la literatura sobre lenguas amenazadas, el tema del "abogado" por la lengua es recurrente. Hemos visto cómo, en el caso del taushiro, la intervención de una misionera lingüista en una época anterior tuvo repercusiones negativas para la sobrevivencia de una comunidad de hablantes, por pequeña que fuera. Con la intervención del Estado que presentamos aquí, por el contrario, dados sus recursos y el respaldo de la legislación actual, se pudo efectuar mejoras en la vivienda de Amadeo y regularizar su estado frente al Seguro Social, para asegurarle buenas condiciones para emprender el proyecto de documentación. En este sentido, la acción del Estado ha sido una de reforzar las circunstancias de vida del hablante en el medio ambiente donde se habla, o se podría hablar, la lengua. Tal acción es contraria a la de la lingüista. En su caso, con todas las buenas intenciones que tuviera de mejorar la vida material de los hijos de Amadeo al llevarlos a vivir a Puerto Rico, logró abstraer a esos hablantes de la lengua taushiro del lugar donde tendría sentido hablar su lengua ancestral y llevarlos a un lugar donde no tendría ninguno.

Como segundo punto, nos parece útil recalcar el tema de "último hablante" 16 , siendo la calificación algo sensacionalista que había recibido Amadeo en la prensa, y que tuvo el efecto de colocarle en una situación de notoriedad no buscada y, por ello, de vulnerabilidad frente a la sociedad. Sin embargo, tal y como sucedió con los

16 De hecho, la categoría de "hablante" puede ser discutida en las lenguas en situación crítica. Al respecto desde el Ministerio de Cultura del Perú se viene discutiendo la necesidad de plantear una nueva tipología de hablantes para este caso, donde se distinga entre "hablante fluido", "hablante latente", "hablante pasivo" y "hablante de herencia" (Ministerio de Cultura, 2019). 


\section{8}

casos documentados por Evans (2010, pp. 207-210) sobre lenguas que se suponía extintas de Asia y Australia, puede surgir una coyuntura que permita el contacto inesperado con algunos hablantes antes desconocidos, por pocos que sean, y la intervención gubernamental oportuna puede llevar a consecuencias positivas. Fue el caso de los hablantes de kusunda, nómadas de la selva de Nepal, por ejemplo. Después de varios esfuerzos, las autoridades nepalesas en el año 2004 acompañaron a Kathmandu a algunos kusunda-hablantes para ayudarles a tramitar sus papeles de identidad; luego de ese contacto viajaron tres lingüistas a la selva para documentar la lengua con los pocos hablantes que sí quedaban (Evans, 2010, p. 208).

En el caso del taushiro es notable el giro utilizado en el informe del Estado, ya citado, al describir su experiencia del trabajo de documentación: 'se han podido romper mitos como el decir que Amadeo García es "el último Taushiro”" (Ministerio de Cultura, 2018, p. 15). Es significativo que uno de los criterios que les sirvió para llegar a esta postura haya sido el hecho de que varios vecinos y parientes de Amadeo, si bien no hablaban la lengua, se declaraban 'pertenecientes al pueblo Taushiro' (Ministerio de Cultura, 2018, p. 15). Esta observación nos parece de suma importancia en el contexto sociocultural latinoamericano, y no solamente peruano, donde la pérdida de competencia lingüística en la lengua originaria no significa necesariamente la pérdida de un sentido de identidad étnica grupal.

Como otro punto, viene al caso referirnos a la documentación sobre cómo tratar temas que tienen que ver con las poblaciones indígenas, publicada por la institución hermana del Ministerio de Cultura peruana, en Chile. En esa publicación se recomienda lo siguiente:

En el caso de las lenguas indígenas, se recomienda no dar por irremediablemente extinta ninguna lengua, ya que como ocurre en el caso de las 6 presentes en Chile, éstas poseen distintos niveles de 
uso, con hablantes parciales y con diferentes trabajos de revitalización en curso, tanto autónomos como con apoyos institucionales (Ministerio de las Culturas, las Artes y el Patrimonio, s/f, p. 10).

A manera de cierre, si bien el proyecto que hemos descrito es un trabajo inicial del Estado peruano en materia de atención a lenguas en situación crítica, no son pocas las señales de que el comienzo es augurador y de que el avance de estas respuestas estatales al problema de pérdida de las lenguas podría ir por buen camino, un camino no esquemático y frío, sino flexible y cercano a las necesidades de los más interesados: los propios ciudadanos que sufren en su propia vida el proceso de desplazamiento lingüístico con sus consecuencias de debilitamiento cultural y social. Las siguientes palabras finales del documento Voces Vivas (Ministerio de Cultura, 2018, p. 15) así lo expresan:

La atención que debe brindar el Estado a través del Ministerio de Cultura es tan diversa como lo es la situación de las lenguas indígenas u originarias del Perú. Los modelos de atención a estas lenguas y a sus pueblos deben ser, por ello, flexibles y adecuarse a las necesidades y deseos de las personas y sus pueblos: hay pueblos que hablan su lengua todo el tiempo y con gran orgullo, hay otros que dejaron de transmitirla décadas atrás y quieren recuperarla, hay pueblos que ya casi la han perdido y solicitan ayuda para documentarla, hay pueblos que ya solo recuerdan palabras de su lengua y añoran los tiempos en que las palabras de los mayores se escuchaban con la magia de lo auténticamente propio. La mejor intervención desde el Estado será aquella que genere una dinámica propia en los miembros del pueblo involucrado, que vea en ellos nacer el interés, las iniciativas de documentación, de recuperación y desarrollo de sus lenguas y sus culturas. 


\section{0}

\section{Referencias bibliográficas}

Adelaar W.F.H. (1999). Unprotected languages: The silent death of the Languages of Northern Peru. En Herzfeld A. y Lastra Y. (Eds.), Las causas sociales de la desaparición y del mantenimiento de las lenguas en las naciones de América (pp. 205-222). Hermosillo, Sonora: Universidad de Sonora.

Casey, N. (2017). Thousands Once Spoke His Language in the Amazon. Now, He's the Only One. Reportaje publicado el 26 de diciembre de 2017. Recuperado de: https://www.nytimes.com/2017/12/26/world/americas/peru-amazon-the-end.html; versión en español "El último hablante de una lengua ancestral de la Amazonía". New York Times. Recuperado de: https://www.nytimes.com/es/2017/12/29/el-ultimo-hablantede-una-lengua-ancestral-de-la-amazonia/

Evans, N. (2010). Dying Words. Endangered Languages and What They Have to Tell Us. Malden, MA/Oxford/Chichester: Wiley-Blackwell

Fowks, J. (2016). “Asesinada en Perú la última mujer hablante de resígaro”. Noticia publicada el 21 de diciembre de 2016. El Pais.com. Recuperado de: https://elpais.com/internacional/2016/12/20/america/1482271957_ 900774.html

Grenoble, L., \& Whaley, L. J. (2006). Saving Languages. An Introduction to Language Revitalization. Cambridge: Cambridge University Press.

Haviland, J. B., \& Flores, J. A. (2011). Bases de la documentación lingüística. México D.F.: Instituto Nacional de Lenguas Indígenas.

Hinton, L. (2011). Revitalization of endangered languages. En: Austin, P., y Sallabank, J. (Eds.), The Cambridge Handbook of Endangered Languages (pp. 291-311). Cambridge: Cambridge University Press.

Luna, R., \& Sánchez, C. (2019). Diccionario básico de Educación e inclusión lingüistica peruana. Lima: Universidad Femenina del Sagrado Corazón.

Ministerio de Cultura (2018). Voces Vivas. Estrategia de atención a lenguas indígenas en situación crítica. Lima: Documento de trabajo.

(2019). Guía de Lineamientos para la documentación de lenguas en situación crítica. Lima: Documento de trabajo.

Ministerio de Educación (2013). Documento Nacional de Lenguas Originarias. Lima: Minedu.

Ministerio de las Culturas, las Artes y el Patrimonio (Gobierno de Chile) (s/f). Recomendaciones para nombrar y escribir sobre pueblos indigenas y sus lenguas. Santiago de Chile. 
Rivadeneyra, D. (2016). "El asesinato de Rosa Andrade es también la muerte de una cultura amazónica”. Noticia publicada el 20 de diciembre de 2016. Lamula.pe. Recuperado de: https://nadiehablade.lamula. pe/2016/12/20/el-asesinato-de-rosa-andrade-ocagane-es-tambien-lamuerte-de-una-cultura-amazonica/danae/

UNESCO. (2003). Vitalidad y peligro de desaparición de las lenguas. Documento elaborado por la Reunión Internacional de Expertos sobre el programa de la UNESCO "Salvaguardia de las lenguas en peligro", en París, del 10 al 12 de marzo de 2003. Recuperado de: http://www.unesco.org/new/fileadmin/MULTIMEDIA/HQ/CLT/pdf/LVE_Spanish_EDITED\%20 FOR\%20PUBLICATION.pdf

\section{Referencias normativas}

Ley $N^{\circ} 29735$, Ley que regula el uso, preservación, desarrollo, recuperación, fomento y difusión de las lenguas originarias del Perú.

Decreto Supremo No 004-2016-MC, Decreto Supremo que aprueba el Reglamento de la Ley $\mathrm{N}^{\circ} 29735$, Ley que regula el uso, preservación, desarrollo, recuperación, fomento y difusión de las lenguas originarias del Perú

Decreto Supremo No 005-2017-MC, Decreto Supremo que aprueba la Política Nacional de Lenguas Originarias, Tradición Oral e Interculturalidad

Decreto Supremo No 011-2018-MINEDU, Decreto Supremo que aprueba el Mapa Etnolingüístico del Perú o Mapa de las lenguas de los Pueblos Indígenas del Perú. 